\title{
Overexpression of SLC38A1 is associated with poorer prognosis in Chinese patients with gastric cancer
}

\author{
Jing Xie ${ }^{1^{*+}}$, Ping Li ${ }^{2 \dagger}$, Hui-feng Gao', Jian-xin Qian ${ }^{3}$, Ling-Yan Yuan ${ }^{3}$ and Jie-jun Wang ${ }^{3 *}$
}

\begin{abstract}
Background: Current literature has demonstrated that host glutamine depletion facilitates tumorigenesis. Likewise, the glutamine transporter SLC38A1 is putatively associated with malignant transformation and tumor progression. Taken together, this forms the premise for undertaking the current study. The twofold aim of this study was to provide insight into whether or not a variance in the expression of SLC38A1 exists between human gastric cancer and healthy human tissues, and to determine how silencing the SLC38A1 gene could affect the proliferation, viability, migration, and invasion of gastric cancer cells.
\end{abstract}

Methods: Immunohistochemical staining was used to analyze the expression of SLC38A1 in gastric cancer tissues and adjacent healthy mucosa in 896 patients with pathologically confirmed gastric cancer who had underwent R0 resection. SH-10-TC cells (a gastric cancer cell line) were used to examine whether silencing SLC38A1 with siRNA could affect cell viability, migration and invasion.

Results: The SLC38A1 protein was very low or undetectable in healthy gastric mucosa. In contrast, strong staining of SLC38A1 protein was found in the cytoplasm in 495 out of the 896 gastric cancer samples. More pronounced SLC38A1 expression in gastric cancer tissues was significantly associated with age, differentiation status, lymph node metastasis, TNM stage and PCNA (proliferating cell nuclear antigen) expression. Upon univariate survival analysis, SLC38A1 expression was correlated with poor survival. Multivariate survival analysis revealed that SLC38A1 was an independent prognostic factor.

Conclusion: SLC38A1 is overexpressed in gastric cancer, which suggests that it is contributory to tumor progression. These results encourage the exploration of SLC38A1 as a target for intervention in gastric cancer.

Keywords: Gastric cancer, Tissue microarray, Immunohistochemistry, SLC38A1, Prognostic factor

\section{Background}

Amino acid transporters are essential for a variety of physiological cellular processes, including uptake of nutrients, energy and chemical metabolism, as well as malignant transformation [1]. Amino acid transporters include system A (ATA1/SNAT1/SLC38A1, ATA2/SNAT2/SLC38A2 and ATA3/SNAT4/SLC38A4), system L (LAT1/SLC7A5 and

\footnotetext{
*Correspondence: jingxie188@163.com; jiejunw@csco.org.cn

${ }^{\dagger}$ Equal contributors

'Department of Integrative Oncology, Fudan University Shanghai Cancer Center; Department of Oncology, Shanghai Medical College, Fudan University, 270 DongAn Road, Shanghai 200032, China

${ }^{3}$ Department of oncology, Changzheng Hospital, the Second Military Medical University, 64 HeTian Road, Shanghai 200003, China

Full list of author information is available at the end of the article
}

LAT2/SLC7A8), and $y+(C A T 2 / S L C 7 A 2)$. Among the various amino acid transporters, system L-type amino acid transporter-1 (LAT-1) is up-regulated in a wide variety of human cancers, including esophageal adenocarcinoma [2], oral squamous cell carcinoma [3], colorectal adenocarcinoma [4], and liver cancer [5]. System A amino acid transporter is also overexpressed in human cancers [5-8]. System A is a $\mathrm{Na}^{+}$-dependent active transport system, known to mediate the uptake of amino acids with small side chains (e.g., alanine, serine, proline and glutamine) [1]. Its activity is highly influenced by $\mathrm{pH}$, cell volume, and a variety of hormones, such as insulin, glucagon, and insulin-like growth factor-I [1].

\section{() Biomed Central}


System A transporter in mammalian cells includes three distinct types, known as amino acid transporters SLC38A1, SLC38A2 and SLC38A4 [9]. These transporters belong to the solute-linked carrier family SLC38, and are differentially expressed among different organs/tissues. SLC38A1 is expressed primarily in the brain and placenta, as opposed to the lungs, liver, spleen and kidneys [10]. SLC38A2 is, on the other hand, ubiquitously expressed in mammalian tissues [9], while SLC38A4 is primarily expressed in the liver [11]. System A transporters are up-regulated in a range of human cancers, including breast cancer and hepatocellular cancer [6,7].

Our previous studies, using gene chip analysis, suggested elevated SLC38A1 mRNA expression in gastric cancer (unpublished data). In the current study, we compared the expression of SLC38A1 in gastric carcinoma in contrast with healthy adjacent gastric mucosa at the protein level. Potential correlation of SLC38A1 with the prognosis was examined using a multivariate analysis, and the biological role of SLC38A1 in proliferation and progression was examined in cultured gastric cancer cells using siRNA.

\section{Methods}

\section{Patients}

This study included 896 patients (median age: 61.4 years; 634 men, 262 women) with histologically confirmed gastric cancer who underwent D2/D3 curative resection at either Changhai or Changzheng Hospital in Shanghai, during a period from 2001 to 2005. Subjects who received neo-adjuvant therapy prior to the surgery were not included. Subjects with stage III disease also received a 5-fluorouracil-based chemotherapeutic regimen for 46 cycles. Patients presenting with neuroendocrine tumors, lymphoma or sarcoma were not included. Adjacent mucosa that was free from cancer cells was used as a healthy control.

The follow-up was conducted via phone conversation and mail in March 2010. Information with regards to survival/death was obtained in 673 cases (median survival: 59.08 months).

Demographic information and the construction of TMA blocks were described previously [12-15]. All tissue specimens were obtained with informed consent, and the use of the human specimens was approved by Institutional Review Board at Changhai and Changzheng Hospitals.

\section{Immunohistochemistry (IHC)}

Immunohistochemical staining was carried out on $4-\mu \mathrm{m}$ paraffin sections after heat-mediated antigen retrieval. Samples were incubated with a human-anti-rabbit polyclonal antibody to SLC38A1 (dilution 1:200; Abcam, Cambridge, U K) overnight at $4^{\circ} \mathrm{C}$. Goat anti-rabbit antibody (dilution 1:4000; Invitrogen, Carlsbad, CA, USA) was used as a secondary antibody. An immunoglobulinnegative control was used to rule out non-specific binding. As for the positive control, we referred to other studies in liver cells by Nobuo Kondoh [6] and in hilar cholangiocarcinoma by Yu WL [16], which indicated the SLC38A1 protein was stained brown and diffused in the cytoplasm. Slides were counterstained with hematoxylin.

Data (staining in cytoplasma) were acquired independently by two investigators (Guan Zhen Yu and Ying Chen) blinded to sample nature using an Olympus CX31 microscope (Olympus, Center Valley, PA, USA), and analyzed using a semi-quantitative scoring system. Staining was graded on a scale of $0-2(0=$ negative staining [no cytoplasmic staining of any tumor cells], $1=$ moderate expression [cytoplasmic staining of $<25 \%$ of tumor cells], and $2=$ high expression [cytoplasmic staining of $\geq 25 \%$ of tumor cells]) as described previously [14,17].

\section{Cell culture and siRNA transfection}

SH-10-TC cells were obtained from Shanghai Institute for Biological Sciences, Chinese Academy of Sciences (CAS), and grown in RPMI-1640 medium containing $10 \%$ FBS. Cells were maintained at $37^{\circ} \mathrm{C}$ in a humidified atmosphere containing $5 \% \mathrm{CO}_{2}$. The experiments were carried out in the exponential phase of growth.

Four pairs of anti-SLC38A1 siRNAs and randomized cocktails of dsRNA as a control were synthesized by GenePharma (Shanghai, China). The siRNA transfection was carried out using Lipofectamine 2000 (Invitrogen, Carlsbad, CA, USA).

\section{Western blot analysis}

Cell lysate containing $100 \mu \mathrm{g}$ protein was resolved on SDS-PAGE, transferred onto PVDF membrane and incubated with an anti-SLC38A1 antibody (dilution, 1:500; Invitrogen, Carlsbad, CA, USA). Protein bands were evaluated using an Odyssey infrared fluorescent scanning system (LI-COR Biosciences, Lincoln, NE, USA) and Scion Image software (NIH, USA). GAPDH was used as an internal control.

\section{Cell viability}

SH-10-TC cells were seeded in 96-well plates at the day before transfection. Cells were counted at $48 \mathrm{~h}, 72 \mathrm{~h}$ and $96 \mathrm{~h}$ after transfection using a microtiter-plate colorimetric WST assay (Cell counting kit-8; Dojindo Laboratories, Kumamoto, Japan) at $450 \mathrm{~nm}$. Experiments were conducted in triplicate.

\section{Transwell migration and invasion assay}

Assays were performed using a modified Boyden chamber (Corning Costar, Rochester, NY, USA) containing a gelatincoated polycarbonate membrane filter $(8-\mu \mathrm{m}$ pore size). 
The upper surface of the filter was coated with $20 \mu \mathrm{L}$ Matrigel $(0.3 \mathrm{mg} / \mathrm{ml}$; BD Biosciences, Bedford, MA, USA). Transfected cells were harvested with a cell dissociation solution (Invitrogen, Carlsbad, CA, USA) and suspended in medium with $1 \%$ bovine serum albumin.

Cells $\left(1 \times 10^{4}\right)$ were added to the upper compartment and allowed to migrate for $6 \mathrm{~h}$ at $37^{\circ} \mathrm{C}$. After $6 \mathrm{~h}$, cells on the upper side of the membrane were removed with a cotton swab. Cells on the bottom surface of the membrane were fixed in 3.7\% paraformaldehyde, stained with hematoxylin for quantification. Data were expressed as the average number of cells per insert.

\section{Statistical analysis}

The relationship between SLC38A1 expression and clinicopathologic parameters was analyzed using the chisquare test. Survival was analyzed using the Kaplan-Meier method and the log-rank test. The prognostic value of clinicopathologic parameters was examined using a Cox proportional hazards regression model for multivariate analysis. All tests were two-sided. $P<0.05$ was considered statistically significant. All statistical analyses were performed using the SPSS statistical software program for Microsoft Windows (SPSS Inc., Chicago, IL, USA).

\section{Results}

\section{SLC38A1 protein in gastric cancer}

The expression of SLC38A1 protein in the healthy gastric mucosa was very low or undetectable (Figure 1A). Strong staining of SLC38A1 protein in the cytoplasm was found in 495 out of the 896 cancer samples in both the well differentiated (Figure 1B), and poorly differentiated cancer cells (Figure 1C). In the cytoplasm, the SLC38A1 protein was stained brown and diffused.

\section{SLC38A1 expression and clinicopathologic factors}

SLC38A1 overexpression was closely associated with old age ( $>60 \mathrm{yrs}$ ), differentiation status (high/moderate), regional lymph node metastasis, TNM stage (III), and positive PCNA expression (Table 1), but not with gender, tumor size, tumor location, operation manner, lymphovascular invasion, depth of tumor invasion, and p53 expression.

\section{Prognostic factors of overall survival}

SLC38A1 expression in cancer tissue was associated with poorer prognosis. The median survival was 46.69 months in patients with SLC38A1-positive cancers, and 69.7 months in subjects with SLC38A1-negative cancers $(P=0.002$; Figure 2). Upon a multivariate analysis, independent

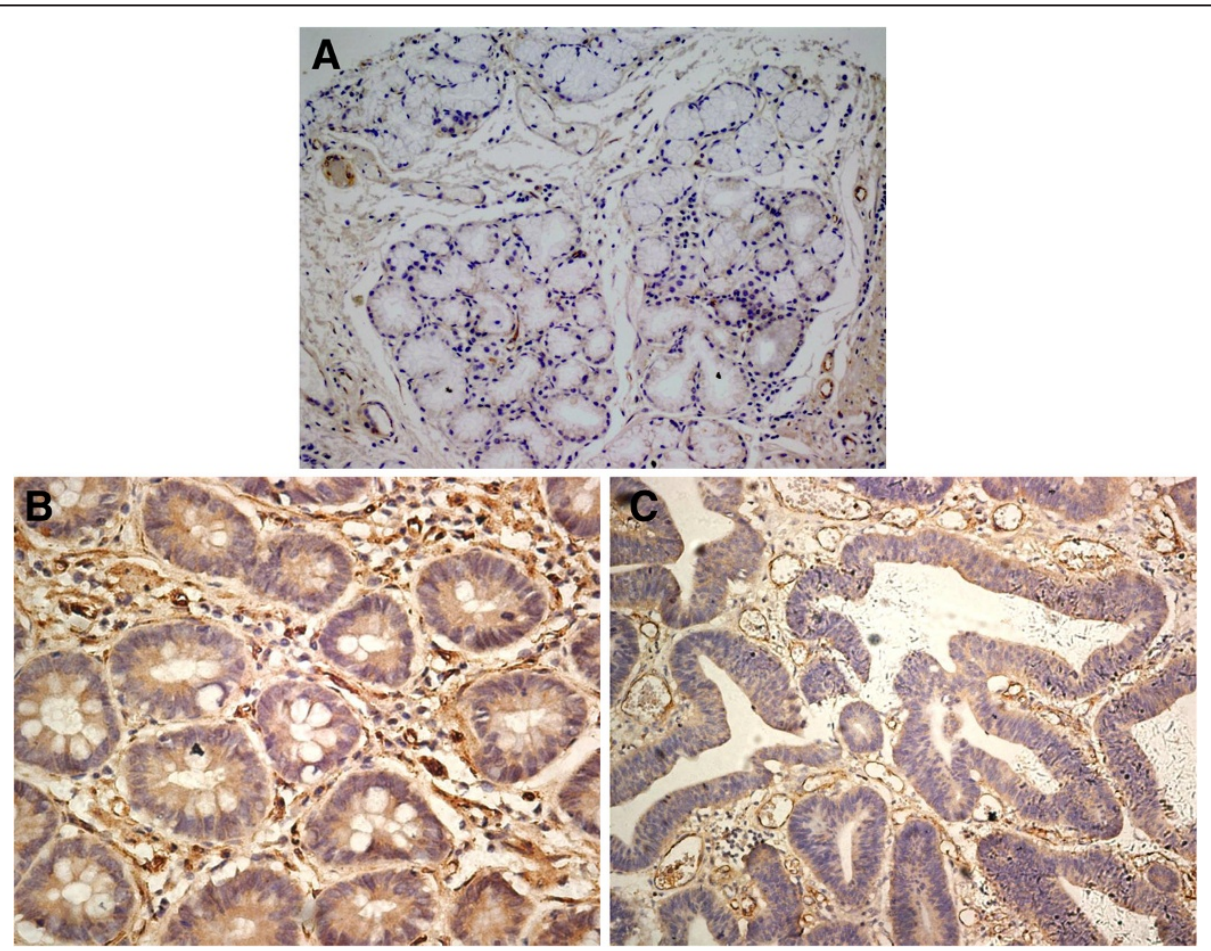

Figure 1 Human gastric cancers and healthy mucosa specimens in tissue microarray were stained with an anti-SLC38A1. (A) Representative healthy gastric tissue without SLC38A1 cytoplasmic expression, (B) Well-differentiated and (C) Morderately-differentiated gastric cancer tissues with positive SLC38A1 expression which was cytoplasm stained brown and diffuse. Magnification × 200 . 
Table 1 Association between SLC38A1 expression and clinicopathological factors of GC patients

\begin{tabular}{|c|c|c|c|}
\hline \multirow[t]{2}{*}{$\begin{array}{l}\text { Clinicopathological } \\
\text { variables }\end{array}$} & \multirow{2}{*}{$\begin{array}{c}\text { Total } \\
\mathbf{n}\end{array}$} & \multicolumn{2}{|c|}{$\begin{array}{c}\text { SLC38A1 positive } \\
\text { expression }\end{array}$} \\
\hline & & $\mathrm{n}$ & $P$ \\
\hline Age & & & 0.007 \\
\hline$\leq 60$ years & 447 & 227 & \\
\hline$>60$ years & 449 & 268 & \\
\hline Sex & & & 0.437 \\
\hline Male & 634 & 345 & \\
\hline Female & 262 & 150 & \\
\hline Location & & & 0.277 \\
\hline Cardia & 144 & 86 & \\
\hline Corpus & 281 & 150 & \\
\hline Antrum & 440 & 246 & \\
\hline Whole & 31 & 13 & \\
\hline Operation manner & & & 0.590 \\
\hline Subtotal gastrectomy & 400 & 217 & \\
\hline Total gastrectomy & 496 & 278 & \\
\hline Size (Diameter) & & & 0.321 \\
\hline$\leq 6 \mathrm{~cm}$ & 706 & 384 & \\
\hline$>6 \mathrm{~cm}$ & 190 & 111 & \\
\hline Differentiation & & & $<0.001$ \\
\hline High/moderate & 553 & 337 & \\
\hline Low/undifferentiated & 343 & 158 & \\
\hline Gastric wall invasion & & & 0.151 \\
\hline $\mathrm{T} 1 / \mathrm{T} 2$ & 308 & 160 & \\
\hline $\mathrm{T} 3 / \mathrm{T} 4$ & 588 & 335 & \\
\hline lymph node metastasis & & & 0.026 \\
\hline Negative & 346 & 175 & \\
\hline Positive & 550 & 320 & \\
\hline TNM stage & & & 0.001 \\
\hline$|/| \mid$ & 427 & 212 & \\
\hline III & 469 & 283 & \\
\hline Lymphovascular invasion & & & 0.275 \\
\hline Negative & 850 & 466 & \\
\hline Positive & 46 & 29 & \\
\hline p53 expression & & & 0.382 \\
\hline Negative & 401 & 228 & \\
\hline Positive & 495 & 267 & \\
\hline PCNA expression & & & 0.012 \\
\hline Negative & 99 & 43 & \\
\hline Positive & 797 & 452 & \\
\hline
\end{tabular}

prognostic factors for overall survival included SLC38A1 expression, differentiation status, lymphovascular invasion, PCNA expression, size and TNM stage (Table 2).

\section{RNAi experiments}

Specific knockdown of endogenous SLC38A1 protein was confirmed by all four siRNAs with Western blot (Figure 3A). siRNA \#2 (si-SLC38A1) reduced the endogenous SLC38A1 transcript by $>70 \%$, and was selected for subsequent experiments.

Compared to parental cells and si-Ctl, si-SLC38A1 decreased the proliferation (Figure $3 \mathrm{~B}$ ), as well as the migration of SH-10-TC cells (Figure 3C), but did not affect cell passage through Matrigel.

\section{Discussion}

Consistent with the physiological and pathological roles of glutamate in cancer development, we found marked differences in the expression of SLC38A1 in gastric cancer relative to adjacent non-cancerous tissue. The uncontrolled proliferation of neoplastic cells requires dramatic changes in energy metabolism [18], in which the primary metabolic fuel and nitrogen source for tumor cells in glutamine [19-21]. Glutamine is known to exert influence on a number of signaling pathways that contribute to tumor growth [22], and is additionally correlated with maintaining the TCA cycle and supporting NADPH production when glucose supply is limited [23].

While glutamine is not an essential amino acid, it plays an important role in maintaining the intestinal barrier structure and immune function. Within the three mammalian system A amino acid transporters, SLC38A1 has the highest affinity for glutamine, and is strongly expressed in glutamatergic neurons [24].

Low blood glutamine concentration has been found in patients with gastric carcinoma and conversely increased in the mucous membrane adjacent to the malignant tissue [25]. It is possible that ectopic activation of SLC38A1 may reflect a compensatory mechanism that confers a survival advantage.

\section{SLC38A1 expression in gastric cancer and other malignancies}

In the present study, we found an increased expression of SLC38A1 in gastric carcinomas, relative to adjacent noncancerous gastric mucosa, suggesting that SLC38A1 might play an important part in gastric cancer malignant transformation. Enhanced SLC38A1 expression has been observed in several other types of malignancies, including liver cancer [6], Hilar cholangiocarcinoma [16] and C6 glioma [26]. An elevated expression of SLC38A1 has been found to be closely linked to differentiation status, lymph node metastasis and TNM staging, and is thus implicated in the growth, invasion, metastasis and progression of gastric carcinomas. 


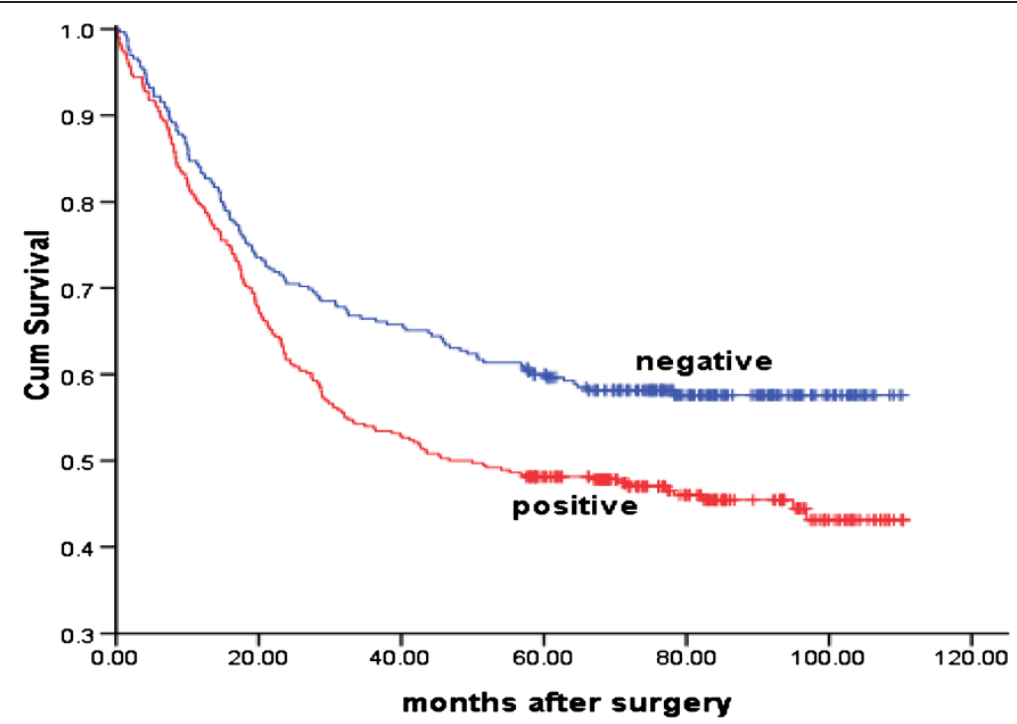

Figure 2 Association between SLC38A1 expression and survival duration in patients with gastric cancer. Kaplan-Meier survival analysis showed median survival of $46.69 \mathrm{vs} .69 .7$ months in patients with positive vs. negative SLC38A1 expression $(P=0.002)$.

\section{Potential mechanism of the action}

Consistent with the observation in HepG2 liver cancer cell lines [6], our study showed that inhibiting SLC38A1 expression with siRNA decreased the growth of cultured $\mathrm{SH}-10-\mathrm{TC}$ cells, thus indicating an overexpression of SLC38A1 contributes to oncogenesis of gastric cancer through promoting cell proliferation. Inhibiting SLC38A1 expression also reduced cell migration, providing evidence for increased cell migration as a mechanism for enhanced metastatic potential, and local invasiveness of SLC38A1expressing tumor cells.

In breast cancer, scientists discovered that 17 betaestradiol specifically increased System A activity by two to four-fold in estrogen receptor positive cell lines, with a maximum stimulation observed $48 \mathrm{~h}$ after estrogentreatment. In estrogen receptor negative cell lines, however, no stimulation was observed, which provided evidence that estrogen receptors play a role in the activation of system A by estrogen [27]. In liver cancer, System A amino acid transporters produced a different kind of inactivation and substrate protection in membrane vesicles and reconstituted proteoliposomes, supporting the hypothesis that there were inherent differences presented in System A carriers in normal and transformed liver tissue [28]. In the current study, we found enhanced SCL38A1 expression in gastric cancer, which supported the implication of glutamine metabolism in tumors [29-31]. Interestingly, certain cancer cell lines are dependent on glutamine despite the fact that glutamine is a nonessential amino acid [32]. To be utilized by tumor cells, glutamine must be transported into tumor cell mitochondria. This implies that SLC38A1 could transport glutamine, and thus play an important role in neoplastic progression/ development.

Table 2 Univariate and multivariate analysis of the prognostic significance of individual clinicopathological factors on survival

\begin{tabular}{|c|c|c|c|c|c|c|c|c|}
\hline & \multicolumn{4}{|c|}{ Univariate analysis } & \multicolumn{4}{|c|}{ Multivariate analysis } \\
\hline & \multirow[t]{2}{*}{ HR } & \multicolumn{2}{|c|}{$95.0 \% \mathrm{Cl}$} & \multirow[t]{2}{*}{$P$ value } & \multirow[t]{2}{*}{ HR } & \multicolumn{2}{|c|}{$95.0 \% \mathrm{Cl}$} & \multirow[t]{2}{*}{$P$ value } \\
\hline & & Lower & Upper & & & Lower & Upper & \\
\hline Size $(\leq 6 \mathrm{~cm}$ vs. $>6 \mathrm{~cm})$ & 1.816 & 1.429 & 2.309 & .000 & 1.327 & 1.039 & 1.696 & .024 \\
\hline TNM (I/II vs. III) & 4.214 & 3.292 & 5.393 & .000 & 3.416 & 2.637 & 4.424 & .000 \\
\hline Differentiation (high/moderate vs. low/undifferentiated) & 1.876 & 1.509 & 2.332 & .000 & 1.565 & 1.249 & 1.960 & .000 \\
\hline Nerve invasion (negative vs. positive) & 2.070 & 1.421 & 3.015 & .000 & 1.353 & .910 & 2.011 & .135 \\
\hline Lymphovascular invasion (negative vs. positive) & 2.664 & 1.770 & 4.011 & .000 & 1.931 & 1.258 & 2.964 & .003 \\
\hline PCNA (negative vs. positive) & 1.794 & 1.174 & 2.742 & 0.007 & 1.695 & 1.098 & 2.617 & .017 \\
\hline P53 (negative vs. positive) & 1.277 & 1.024 & 1.593 & 0.03 & 1.046 & .835 & 1.310 & .695 \\
\hline SLC38A1 (negative vs. positive) & 1.191 & 1.065 & 1.332 & 0.002 & 1.122 & 1.001 & 1.258 & .041 \\
\hline
\end{tabular}




\section{A}
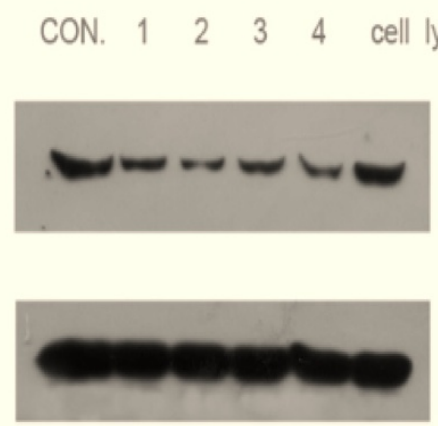

LANE $\quad 1 \quad 2 \quad 2 \quad 3 \quad 4 \quad 56$

C
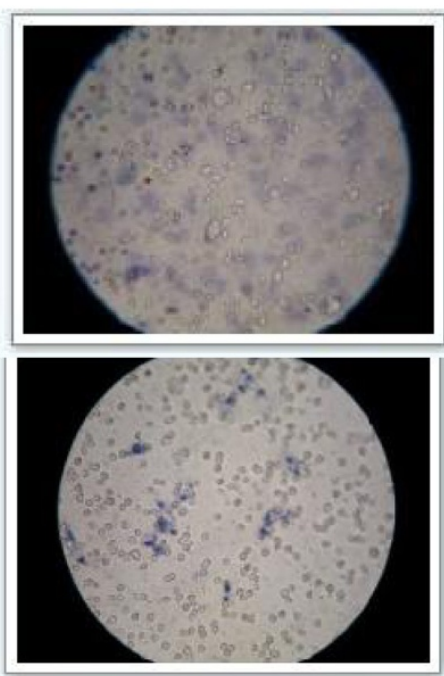

\section{$65 k d$}

GAPDH
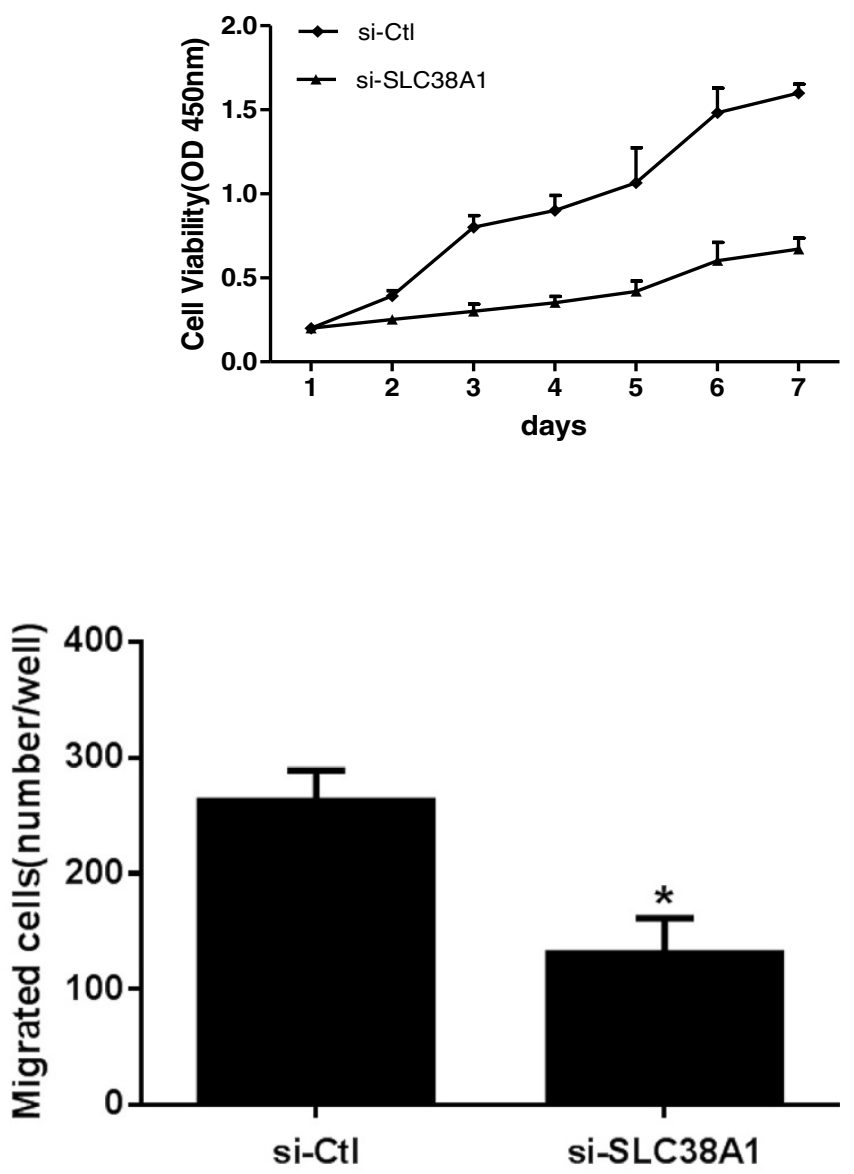

Figure 3 Silencing SLC38A1 with siRNA in SH-10-TC cells and experiments in vitro. (A) Representative Western blot in the siRNA experiments. siRNA \#2 reduced the SLC38A1 transcript by $>70 \%$ in comparison to scrambled control (lane1 and 6). GAPDH was used as the internal control. (B) CCK-8 assay shows si-SLC38A1 significantly inhibited the cell growth of SH-10-TC cells. (C) Upper panel: si-SLC38A1 decreased the migration of SH-10-TC cells in transwell chambers, compared to parental cells and si-Ctl group. Lower panel: migrated cells on the surface of the membrane (Columns, mean; bars, SD. ${ }^{*}, P<0.01$ vs. scrambled control).

\section{Association of SLC38A1 expression with}

\section{clinicopathological characteristics as well as prognosis} in patients with GC

Upon further investigation of the relationship between SLC38A1 and clinicopathological factors, we found that overexpression of SLC38A1 was strongly associated with patient age, differentiation status, lymph node metastasis, TNM stage and the expression of PCNA, whereas no significant association was found in patient gender, tumor size, tumor location, operation manner, lymphovascular invasion, depth of tumor invasion, and p53 expression. These results indicated that SLC38A1 plays a central role in the malignant progression of gastric carcinomas.
Risk factors for gastric cancers have been reported in a number of studies, including differentiation, [33] nerve invasion [33], lymphovascular invasion [33], size [13,34], TNM stage [34], and some molecular markers [35]. Our study confirmed that differentiation, lymphovascular invasion and the TNM stage were independent predictors for gastric cancer. We additionally found that SLC38A1 expression alone was a prognostic factor, with its prognostic value in multivariate survival analysis for patients who underwent gastrectomy. Therefore, we supposed that overexpression of SLC38A1 is a significant factor associated with a poor prognosis, and might be a marker to forecast gastric cancer patients' recurrence and survival. Secondly, 
patients with poorer prognosis should be monitored more closely and/or undergo more positive treatment.

\section{Conclusion}

In conclusion, our study showed that SLC38A1 expression was closely associated with age, differentiation status, lymph node metastasis, TNM stage and PCNA expression, as well as a worse prognosis in patients with gastric cancer. The results from the experiments using cultured gastric cancer cells indicated that SLC38A1 expression could be used as an indicator of disease aggressiveness. Overall, these findings could be useful in developing a novel molecular target for individualized treatment of gastric cancer.

\section{Abbreviations \\ SLC38A1: Solute carrier family 38, member 1; TMA: Tissue microarray; \\ PCNA: Proliferating cell nuclear antigen; TCA: Tricarboxylicacidcycle.}

\section{Competing interests}

The authors declared that they have no competing interests.

\section{Authors' contributions}

JX participated in the study design, collected patient material and drafted the manuscript. PL collected patient material, performed statistical analyses and revised the manuscript for important intellectual content. HFG participated in the study design and revised the manuscript for important intellectual content. JXQ collected patient material. LYY collected patient material. JJW conceived of the study, and participated in its design and coordination and revised the manuscript for important intellectual content. All authors read and approved the final manuscript.

\section{Authors' information}

JX, MD of oncology, was involved the application of National Natural Science Foundation associated with gastric cancer. Acquire the Foundation of collaboration with Comprehensive Integrative Medicine institute (CIMI), Republic of Korea. She is the secretary of Committee of Minimally Invasive Therapy in Oncology, Shanghai Anti-Cancer Association.

$\mathrm{PL}$, MS of oncology, is involved the application of National Natural Science Foundation associated with gastric cancer. She is the recipient of a Doctor Innovation Foundation of the Medical of Shanghai Jiao Tong University. HFG, MS of TCM, is involved the application of National Natural Science Foundation associated with pancreatic cancer. HFG has accumulated experiences in the follow-up and analysis the cases.

$J X Q$, MS of oncology, Vice Director, Department of Oncology, Changzheng Hospital, Shanghai, is involved the application of National Natural Science Foundation associated with gastric cancer.

LYY, MS of oncology, is involved the application of National Natural Science Foundation associated with gastric cancer.

JJW, Director, Department of Oncology, Changzheng Hospital, Shanghai. Director, Department of Oncology. He is the recipient of an award from the National Natural Science Foundation associated with gastric cancer. JJW has long been engaged in cancer research, especially gastric cancer.

\section{Acknowledgements}

The authors thank Guan-zhen Yu, Chen Ying, Xi Wang, Jun Pan, Ke Liu and Zhou Zhou for the follow-up information collection assistance.

\section{Author details}

'Department of Integrative Oncology, Fudan University Shanghai Cancer Center; Department of Oncology, Shanghai Medical College, Fudan University, 270 DongAn Road, Shanghai 200032, China. ${ }^{2}$ Stem Cell Research Center, Renji Hospital, School of Medicine, Shanghai Jiaotong University, Shanghai 200127, China. ${ }^{3}$ Department of oncology, Changzheng Hospital, the Second Military Medical University, 64 HeTian Road, Shanghai 200003, China.
Received: 10 April 2013 Accepted: 31 March 2014

Published: 9 April 2014

\section{References}

1. McGivan JD, Pastor-Anglada M: Regulatory and molecular aspects of mammalian amino acid transport. Biochem J 1994, 299:321-334.

2. Lin J, Raoof DA, Thomas DG, Greenson JK, Giordano TJ, Robinson GS, Bourner MJ, Bauer CT, Orringer MB, Beer DG: L-type amino acid transporter-1 overexpression and melphalan sensitivity in Barrett's adenocarcinoma. Neoplasia 2004, 6:74-84.

3. Kim DK, Ahn SG, Park JC, Kanai Y, Endou H, Yoon JH: Expression of L-type amino acid transporter 1 (LAT1) and 4F2 heavy chain (4F2hc) in oral squamous cell carcinoma and its precusorlesions. Anticancer Res 2000, 24:1671-1675.

4. Haase C, Bergmann R, Fuechtner F, Hoepping A, Pietzsch J: L-type amino acid transporters LAT1 and LAT4 in cancer: uptake of 3-0-methyl-6-18 F-fluoro-L-dopa in human adenocarcinoma and squamous cell carcinoma in vitro and in vivo. J Nucl Med 2007, 48:2063-2071.

5. Campbell WA, Thompson NL: Overexpression of LAT1/CD98 light chain is sufficient to increase system L-amino acid transport activity in mouse hepatocytes but not fibroblasts. J Biol Chem 2001, 276:16877-16884.

6. Kondoh N, Imazeki N, Arai M, Hada A, Hatsuse K, Matsuo H, Matsubara O, Ohkura S, Yamamoto M: Activation of a system A amino acid transporter, ATA1/SLC38A1, in human hepatocellular carcinoma and preneoplastic liver tissues. Int J Oncol 2007, 31:81-87.

7. Wu Y, Shen D, Chen Z, Clayton S, Vadgama JV: Taxol induced apoptosis regulates amino acid transport in breast cancer cells. Apoptosis 2007, 12:593-612.

8. Novak D, Quiggle F, Haafiz A: Impact of forskolin and amino acid depletion upon System A activity and SNAT expression in BeWocells. Biochimie 2006, 88:39-44.

9. Sugawara M, Nakanishi T, Fei YJ, Huang W, Ganapathy ME, Leibach FH, Ganapathy V: Cloning of an amino acid transporter with functional characteristics and tissue expression pattern identical to that of system A. J Biol Chem 2000, 275:16473-16477.

10. Varoqui $H$, Zhu $H$, Yao D, Ming $H$, Erickson JD: Cloning and functional identification of a neuronal glutamine transporter. J Biol Chem 2000 275:4049-4054.

11. Hatanaka T, Huang W, Ling R, Prasad PD, Sugawara M, Leibach FH, Ganapathy V: Evidence for the transport of neutral as well as cationic amino acids by ATA3, a novel and liver-specific subtype of amino acid transport system A. Biochim Biophys Acta 2001, 1510:10-17.

12. Liu K, Wang G, Ding $H$, Chen $Y, Y u$ G, Wang J: Downregulation of metastasis suppressor 1(MTSS1) is associated with nodal metastasis and poor outcome in Chinese patients with gastric cancer. BMC Cancer 2010, 10:428.

13. Yu G, Wang J, Chen Y, Wang X, Pan J, Li G, Jia Z, Li Q, Yao JC, Xie K: Overexpression of phosphorylated mammalian target of rapamycin predicts lymph node metastasis and prognosis of chinese patients with gastric cancer. Clin Cancer Res 2009, 15:1821-1829.

14. Yu G, Wang J, Chen Y, Wang X, Pan J, Li Q, Xie K: Tissue microarray analysis reveals strong clinical evidence for a close association between loss of annexin A1 expression and nodal metastasis in gastric cancer. Clin Exp Metastasis 2008, 25:695-702.

15. Yu GZ, Chen Y, Wang JJ: Overexpression of Grb2/HER2 signaling in Chinese gastric cancer: their relationship with clinicopathological parameters and prognostic significance. J Cancer Res Clin Oncol 2009, 135:1331-1339.

16. Yu WL, Cong WM, Zhang Y, Chen Y, Wang F, Yu G: Overexpression of ATA1/SLC38A1 predicts future recurrence and death in Chinese patients with hilarcholangiocarcinoma. J Surg Res 2011, 171:663-668.

17. Peng Z, Wei D, Wang L, Tang H, Zhang J, Le X, Jia Z, Li Q, Xie K: RUNX3 inhibits the expression of vascular endothelial growth factor and reduces the angiogenesis, growth, and metastasis of human gastric cancer. Clin Cancer Res 2006, 12:6386-6394.

18. Hanahan D, Weinberg RA: Hallmarks of cancer: the next generation. Cell 2011, 144:646-674.

19. Yuneva M: Finding an "Achilles' heel" of cancer: the role of glucose and glutamine metabolism in the survival of transformed cells. Cell Cycle 2008, 7:2083-2089. 
20. Viallard V, Denis C, Trocheris V, Murat JC: Effect of glutamine deprivation and glutamate or ammonium chloride addition on growth rate, metabolism and differentiation of human colon cancer cell-line HT29. Int J Biochem 1986, 18:263-269.

21. Medina MA, Sánchez-Jiménez F, Márquez J, Rodríguez-Quesada A, Nuñez-De-Castro I: Relevance of glutamine metabolism to tumor cell growth. Mol Cell Biochem 1992, 113:1-15.

22. DeBerardinis RJ, Cheng T: Q's next: the diverse functions of glutamine in metabolism, cell biology and cancer. Oncogene 2010, 29:313-324.

23. Kaelin WG Jr, Thompson CB: Q\&A: Cancer: clues from cell metabolism. Nature 2010, 465:562-564.

24. Weiss MD, Derazi S, Rossignol C, Varoqui H, Erickson JD, Kilberg MS, Anderson KJ: Ontogeny of the neutral amino acid transporter SAT1/ATA1 in rat brain. Brain Res Dev Brain Res 2003, 143:151-159.

25. Berezov TT, Aptekar LS, Zinevich AK: Specificity of glutamine metabolism in pre-tumorous diseases and cancer of the human stomach. Vopr Med Khim 1977, 23:555-558.

26. Ogura M, Takarada T, Nakamichi N, Kawagoe H, Sako A, Nakazato R, Yoneda Y: Exacerbated vulnerability to oxidative stress in astrocytic C6 glioma cells with stable overexpression of the glutamine transporter slc38a1. Neurochem Int 2011, 58:504-511.

27. Bhat HK, Vadgama JV: Role of estrogen receptor in the regulation of estrogen induced amino acid transport of System A in breast cancer and other receptor positive tumor cells. Int J Mol Med 2002, 9:271-279.

28. Dudeck KL, Dudenhausen EE, Chiles TC, Fafournoux P, Kilberg MS: Evidence for inherent differences in the system A carrier from normal and transformed liver tissue. Differential inactivation and substrate protection in membrane vesicles and reconstituted proteoliposomes. J Biol Chem 1987, 262:12565-12569.

29. Okada A, Takehara H, Yoshida K, Nishi M, Miyake H, Kita Y, Komi N: Increased aspartate and glutamate levels in both gastric and colon cancer tissues. Tokushima J Exp Med 1993, 40:19-25.

30. Medina MA: Glutamine and cancer. J Nutr 2001, 131:2539S-2542S.

31. Lu W, Pelicano H, Huang P: Cancer metabolism: is glutamine sweeter than glucose? Cancer Cell 2010, 18:199-200.

32. Wise DR, Thompson CB: Glutamine addiction: a new therapeutic target in cancer. Trends Biochem Sci 2010, 35:427-433.

33. National Comprehensive Cancer Network: NCCN Clinical Practice Guidelines in Oncology: gastric cancer, V.1.; 2012. Available at: http://www.nccn.org/ professionals/physician_gls/f_guidelines.asp\#gastric.

34. Zhan YQ SXW, Li W, Chen YB, Xu L, Guan YX, Li YF, Xu DZ: Multivariate prognostic analysis in gastric carcinoma patients after radical operation. Ai Zheng 2005, 24(5):596-599.

35. Victorzon M, Nordling S, Haglund C, Lundin J, Roberts PJ: Expression of p53 protein as a prognostic factor in patients with gastric cancer. Eur $J$ Cancer 1996, 32A:215-220.

doi:10.1186/1471-230X-14-70

Cite this article as: Xie et al:: Overexpression of SLC38A1 is associated with poorer prognosis in Chinese patients with gastric cancer. $B M C$ Gastroenterology 2014 14:70.

\section{Submit your next manuscript to BioMed Central and take full advantage of:}

- Convenient online submission

- Thorough peer review

- No space constraints or color figure charges

- Immediate publication on acceptance

- Inclusion in PubMed, CAS, Scopus and Google Scholar

- Research which is freely available for redistribution

Submit your manuscript at www.biomedcentral.com/submit 